\title{
The Coping with the Oppressed Feelings Program: A Pilot Feasibility Study for Employed Female Caregivers of Aging Parents
}

\section{Yumi Hashizume*}

Division of Health Innovation and Nursing, Gerontological Nursing \& Caring, University of Tsukuba, Japan

\begin{abstract}
Aim: The purpose of this study was to examine the feasibility, acceptability, and short-term outcomes of a theoretically based educational counseling intervention designed to decrease the caregiving burden, gender role pressures, and depressed mood and to increase role acceptance in employed female caregivers.

Methods: A single group, pre- and post-test design was utilized. Eight middle-aged, Japanese working female caregivers who had a minimum of a high school education participated, four of whom participated with a spouse. Feasibility and acceptability were assessed with the completion rate of the intervention and at-home assignments. Acceptability was assessed with the caregivers' feedback regarding the intervention. Standardized questionnaires were used to measure the short-term impact of the intervention. Four sets of educational materials were delivered at one- to three-week intervals during five 1-hour face-to-face sessions with a nurse educator over the course of seven weeks. Four sessions were provided to the caregivers, and one session was given to both the caregiver and her spouse.

Results: Certain changes occurred in the caregivers' expressed feelings, in the caregiving burden, and in the self-care time during the weekends.

Conclusions: A brief, theoretically based nurse-delivered educational counseling program benefited employed female caregivers.
\end{abstract}

Keywords

Emotional stress, Family caregivers, Gender issues, Feasibility study, Pilot project

\section{Introduction}

Thousands of older, Japanese adults are cared for by employed female family members. In 2016, 27\% (34 million) of the population was over 65 years of age, and approximately $18 \%$ (6 million) were care receivers [1]. An estimated 2.9 million women are home-based family caregivers, and $32 \%$ of these women $(931,300)$ are middle-aged [2]. The desire for employment among married woman has increased, and $75 \%$ or more of the female workforce comprises women aged 45-54 years old [3].

Women desire employment because of Japan's slow economic recovery, because of the restructuring of the lifetime employment system, and because of the citizens' loss of confidence in the national social welfare system $[4,5]$. A new policy that promotes home-based care for older adults designed to reduce the costs of medical-nursing care [6] places substantial pressure on an already busy daily routine of working family caregivers [7]. Family care leave is a formal service that promotes the work-life balance of female caregivers but is utilized by less than $3 \%$ of eligible caregivers [8]. In 2010, approximately 80,000 family caregivers terminated their employment [2], and more than $50 \%$ were middle-aged women [9]. A large survey managed to assess the psy-

\begin{abstract}
${ }^{*}$ Corresponding author: Yumi Hashizume, RN, RPHN, Ph.D, Faculty of Medicine, Division of Health Innovation and Nursing, Gerontological Nursing \& Caring, University of Tsukuba, 1-1-1 Tennoudai, Tsukuba, Ibaraki, 305-8577, Japan, E-mail: hashizume.yumi.gu@u.tsukuba.ac.jp
\end{abstract}

Accepted: July 30, 2018; Published online: August 01, 2018

Citation: Hashizume Y (2018) The Coping with the Oppressed Feelings Program: A Pilot Feasibility Study for Employed Female Caregivers of Aging Parents. J Nurs Pract 2(2):62-72

Copyright: (c) 2018 Hashizume $Y$. This is an open-access article distributed under the terms of the Creative Commons Attribution License, which permits unrestricted use, distribution, and reproduction in any medium, provided the original author and source are credited. 
Citation: Hashizume Y (2018) The Coping with the Oppressed Feelings Program: A Pilot Feasibility Study for Employed Female Caregivers of Aging Parents. J Nurs Pract 2(2):62-72

cho-physical condition of home-based family caregivers and revealed that slightly more than $25 \%$ of them were depressed [10]. Even though they are not forced to resign, a depressed mood is said to be as one of the major mental disorders of the working population [11]. The exact proportion of mental health disorder cases among working female caregivers has not been reported yet; $\mathrm{Mi}$ negishi and Shiwatari (2015) [12] observed 422 female care-workers regarding depressed moods and reportedthat more than $40 \%$ were clinically depressed. Compared to those who were not clinically depressed, the depressed female care-workers were working significantly harder to balance their job and housework tasks [12]. For the nursing profession, the top three ranked reasons for resignation included nurses' health problems and care for their families [13]. These findings support that working female caregivers need mental health care.

The feelings of these caregivers fluctuate due to the contradictory influences of governmental policy and the less obvious, deeply embedded, normative cultural beliefs regarding caregiver responsibilities. The current study hypothesizes that Japanese, middle-aged, employed female caregivers have incorporated their role as part of their own identities and are culturally obligated by society to be "good caregivers" by taking care of their aging parents.

The conceptual framework of the problem currently being studied comprises the following four concepts 1) Japanese gender role pressures, 2) Oppressed feelings or demands, 3) Feelings of acceptance by the spouse, and 4) Caregiving burden. Based on the results of two former studies, a literature review concerning the gender issues affecting contemporary Japanese female caregivers of elderly relatives and a grounded-theory study that explored the lived experiences of employed female caregivers within a cultural frame of reference, while also drawing on other international literature, these concepts have been reported elsewhere $[7,14]$.

Japanese gender roles include attitudinal behaviors that reflect societal expectations that women should maintain harmony by valuing older adults or males and by providing caregiving, along with valuing the protection of family privacy and avoiding inconveniencing others $[7,14,15]$. Caregiving is imprinted deeply in the psyche of the caregivers and further operates as a sense of norm or an invisible pressure from social public defined as Japanese gender role pressure. This role is reflected in the typical life course of traditional middle-aged Japanese women, which is to work outside of the home for the prosperity of the household if the elders are in good health and then to leave their jobs to dedicate themselves to housework and to caregiving for the elderly person's entirelife.

Oppressed feelings or demands are defined as nega- tive feelings toward one's self or demands on task-sharing and valuing personal life. These feelings provoke the internalization of the burden of objective Japanese gender role pressure, which encourages the prioritization of caregiving and housework tasks over self-care, without complaining about the aforementioned values of protection of family privacy and with avoiding inconveniencing others $[7,14,15]$. Japanese gender role pressure has negative consequences for women and results in the relinquishment of the self to meet the needs of the agingparent, husband, and general household, engendering feelings of guilt and shame toward themselves $[7,14]$.

Feelings of acceptance by the spouse are defined as demands of the caregivers to their husbands. Based on the Japanese gender role pressure, the value of avoiding inconveniencing their spouses makes female caregivers apologetic toward them for requesting task-sharing, and it further harbors skeptical feelings, impeding the frank expression of any oppressed feelings or demands. In Japan, role is supported by the husband's communication style, which tends to be overbearing and not receptive to the wife's complaints, and the wives tends to be sympathetic and dependent [16-18].

If there is a lack of spousal support for female caregivers, it is difficult for women to make time for self-care, both interpersonally and logistically. The results from a completed study on time management revealed that selfcare time on weekends for female caregivers was shorter than that for males (female, 5 hours 10 minutes vs. males, 6 hours 49 minutes). Additionally, time spent doing housework was much longer for females than for males (4 hours 36 minutes vs. 1 hour 29 minutes, respectively) [19].

These factors increase the final concept of the caregiving burden, which is defined as the strain on the caregivers provoked by internalized burdens from objective Japanese gender role pressure, which encourages caregiving and housework over self-care. This outcome is in addition to a full- or part-time workload, to the absence of complaining about oppressed feelings or demands, and to the aforementioned values of protection of family privacy and avoiding inconveniencing others $[7,14,15]$. As a result, the caregivers may experience caregiving burden, depressed mood and lower role acceptance [7].

To date, there have been a number of intervention studies on Japanese family caregivers [20-22]. Among them, Mochizuki (2005) [20] attempted RCT for family caregivers by managing a two-week psychoeducational intervention program that aimed to reduce caregiving burden and to improve the feeling of satisfaction of caregiving. Two sessions were performed, including one face-to-face meeting to listen to and sympathize with the caregiver's feelings and to encourage them by providing a brochure that contained information on coping with a 
Citation: Hashizume Y (2018) The Coping with the Oppressed Feelings Program: A Pilot Feasibility Study for Employed Female Caregivers of Aging Parents. J Nurs Pract 2(2):62-72

caregiving life. One telephone conversation occurred after the week of the first session as a follow-up. Although the researcher hypothesized a relationship between the social norm and caregiving burden of daughter-in-law caregivers, no theoretical background or framework was shown for the program or for the intervention material. There was no significant difference in the feelings of satisfaction of caregiving, despite the impact on the caregiving burden. Mochizuki concluded that the lack of impact was due to the short period of intervention.

Therefore, there are no known, theory-based, culturally appropriate programs to assist working female caregivers in dealing with the magnitude of caregiving stressors. The Coping with Oppressed Feelings Program (COFP) was designed to contribute to caregivers' skills for coping with distress and for promoting self-care within a theoretical framework.

\section{Study Aim}

The purpose of this study was to evaluate the feasibility, acceptability and short-term impact of the COFP with respect to caregiver behavioral and emotional outcomes.

\section{Methods}

\section{Study design}

A single design was used, and the impact was evaluated using comparisons between pre- and post-intervention scores on standardized questionnaires. Some items were developed.

\section{Participants, recruitment and protocol}

After obtaining signed informed consent from the director of the caregiving industry or from public health organizations, caregivers were recruited in three different districts of one prefecture in Japan. The directors, managers or organization administrators recommended a few eligible caregivers, and a trained nurse educator (NE; the author) contacted them face-to-face at their work place. In addition, convenience and snow-ball sampling (a participant recommended other eligible caregivers) were used to avoid provoking resistance from eligible participants based on their motivation to protect family privacy. NE recruited caregivers who met the following study criteria: a) Married, living with their spouse and employed (including part time and self-employment); b) Regularly enrolled in the caregiving of an elderly parent or parent-inlaw, regardless of whether the caregiver was living with the elderly family members or not; and c) The elderly family member was house-bound, chair-bound or bed-bound, in reference to the criteria of the Japanese Ministry of Health and Welfare. The following were the exclusion criteria: a) Separated or divorced, b) Having no children and c) Irregular frequency in caregiving for the elderly members.
After obtaining signed informed consent, baseline measurements were assessed, followed by the first intervention session. Four sessions were given to the caregivers, with one joint session provided for the caregiver and her spouse. These sessions were scheduled and completed by NE with a semi-structured script in a private room at the caregiving facility or at the caregivers' homes. All the sessions were recorded upon consent.

The length of the entire intervention was seven weeks from the beginning of the first session to the last leg of the fifth session. Five one-hour face-to-face sessions at one- to three-week intervals were given. The intervention period was based on the systematic review or the meta-analysis on interventions for family caregivers [21,23], which has been suggested to improve mental health outcomes.

\section{Theoretical framework and study hypothesis}

The COFP was derived from three theories: Japanese gender role theory [7], the theory of structured writing [24], and social cognitive theory [25]. The Japanese gender role theory was developed based on two former studies $[7,14]$ and was used to further compose the framework of the intervention.

Japanese gender role theory and the theory of structured writing was applied when creating the study materials. Japanese gender role theory and social cognitive theory were applied when structuring the intervention.

In applying the theory of structured writing, "expressive writing" was used in the current study to improve emotional health by providing a release for previously inhibited thoughts or behaviors, thus facilitating the development of stress-related thoughts so that the caregivers habituated to them $[24,26]$. In applying social cognitive theory, the concepts of observational learning, reinforcement, and emotional coping responses [25] were used in the study materials, including one joint session with both spouses.

Seven conceptual outcomes [expression of oppressed feelings or demands (here after, expression of feelings), feelings of acceptance by the spouse (acceptance by spouse), self-care, caregiving burden, Japanese gender role pressure (gender pressure), depressed mood and role acceptance] were observed and assessed. As a consequence, the author proposed the following outcome/hypothesis. The primary outcomes of the intervention were as follows: a) Caregiver feeling released from the above feelings or demands by raising awareness and normalizing it, b) Addressing the demands of emotional support and task-sharing with the spouse by re-examining his interpersonal support and feeling free to express the feelings, which further heightens acceptance by spouse, 
Citation: Hashizume Y (2018) The Coping with the Oppressed Feelings Program: A Pilot Feasibility Study for Employed Female Caregivers of Aging Parents. J Nurs Pract 2(2):62-72

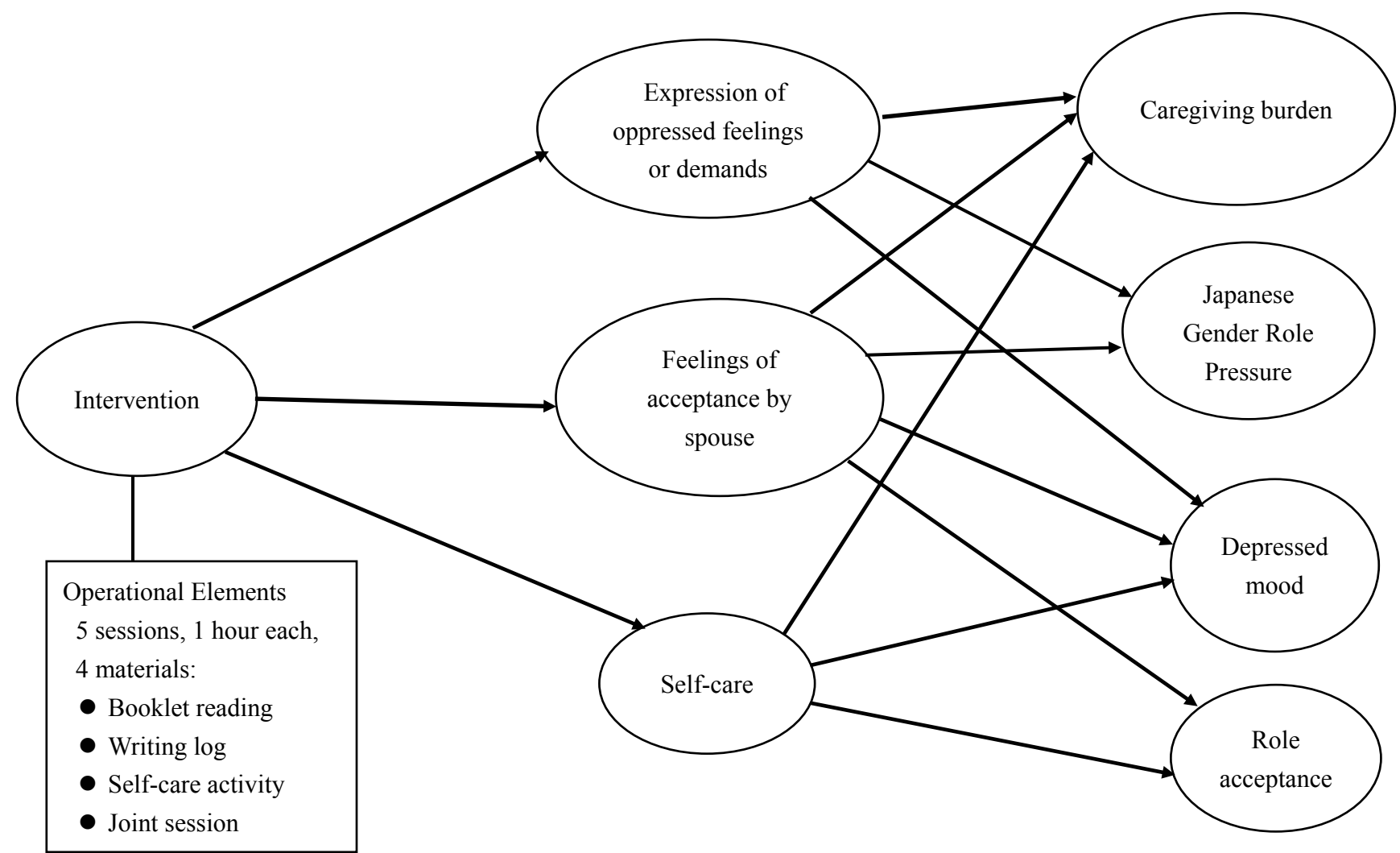

Figure 1: Moving from left to right, the Coping with the Oppressed Feelings Program (COFP) intervention is designed to increase the caregiver's expression of oppressed feelings or demands to spouse, which decreases the caregiving burden, the Japanese gender role pressure, and the depressed mood. The intervention also increases feelings of acceptance by the spouse, which decreases caregiving burden, Japanese gender role pressure and depressed mood and increases role acceptance. The intervention further increases the amount of self-care, which decreases caregiving burden and depressed mood and increases role acceptance.

COFP is derived from three theories: the Japanese gender role theory [7,14], the theory of structured writing (Pennebaker, 2004) [24] and the social cognitive theory [25]. Two theories (Japanese gender role and structured writing theory) were used for the content, which included at-home assignments, and two (Japanese gender role and social cognitive theory) were used for the structure.

As for the operational elements, the COFP included five one-hour face-to-face sessions managed by a trained nurse educator (NE; the author) at one- to three-week intervals with a semi-structured script. Four sessions were for the caregivers, and one session (session four) was provided for the caregiver and her spouse (joint session). The length of the entire intervention was seven weeks.

The COFP consisted of four materials: a booklet, a writing log, a tip-sheet for self-care activities, and a joint session. See Table 1 for session description and materials.

and c) Engaging in self-care activities on a more regular basis. The secondary outcomes were to decrease caregiving burden, gender pressure and depressed mood and to increase role acceptance among caregivers in relation to the pre-intervention measurements. Figure 1 shows the relationship between the intervention and the concepts graphically.

\section{Intervention}

The COFP consisted of four study materials: a booklet, a writing $\log$ (here after, the $\log$ ), a tip-sheet for self-care activities (tip-sheet), and a joint session with both spouses. The joint session served as an educational resource for the caregiver regarding the acceptance by spouse element and was designed for the purpose of the intervention. See Table 1 for the session descriptions and materials.

\section{Study measures}

This study was evaluated by assessing its feasibility, acceptability and short-term impact.

Feasibility and acceptability were assessed by examining the 1) Completion rate of the intervention sessions and 2) Completion rate of the at-home assignments. Acceptability was further assessed by the caregivers' perception of what they had gained from participating in COFP and their feedback regarding the importance of the intervention, which was provided mainly in the exit interview. 
Citation: Hashizume Y (2018) The Coping with the Oppressed Feelings Program: A Pilot Feasibility Study for Employed Female Caregivers of Aging Parents. J Nurs Pract 2(2):62-72

Table 1: Session description and materials.

S. No Session One (S1). Opening up to caring for yourself

1. This session was conducted to raise awareness of and normalize caregivers' oppressed feelings or demands within a culturally appropriate context.

The booklet (You're not alone: what I want you to know about your emotional health) contained quotes from working female caregivers regarding their oppressed feelings or demands, which were derived from the results of a previous qualitative study [7] addressing the demands of the caregivers on emotional support and task-sharing from her spouse, and the caregivers' need for self-care. Booklet reading assisted caregivers in feeling that they were not alone by informing them that caregivers experienced those feelings or demands. The writing log (My notebook) was implemented to assist the caregivers in expressing and releasing distress.

The caregivers were encouraged to write about any sensitive and/or negative circumstances that they had experienced but did not feel like talking about with others for four days. Topics were suggested and changed as the project proceeded. A stopwatch and compact shredder were provided to destroy and dispose of the contents. In accordance with the value placed on protecting family privacy in Japan, the contents of the log were disposed of four days after its completion.

However, the caregivers were welcomed to submit the log contents to nurse educator (NE; the author) if they desired to do so. In light of this value, NE avoided discussing the contents with the caregiver.

Materials: Baseline measurements, a booklet, and a writing log.

2.

Session Two (S2). Being skilled at caring for yourself

One week after S1, the caregivers learned how to become skilled at caring for themselves. A tip-sheet for self-care activities, which contained leisure activities related to self-care in women, was provided as an at-home assignment to encourage caregivers to stay motivated when undertaking with certain activities.

NE further asked each caregiver to jointly participate in the fourth session (session four: S4) with her spouse. If the couple agree to participate in S4, NE asked the caregiver to provide her spouse with the booklet and ask her husband to participate in booklet reading.

The booklet reading helped the spouse learn to be aware of his wife's oppressed feelings or demands.

Materials: Tip-sheet for self-care activities for caregivers, booklet (the same material provided to the caregiver for spouse).

3. Session Three (S3-i and S3-ii). Reflecting upon oneself as an organizer of self-care

In S3-i, which was conducted two weeks after S2, NE evaluated the caregivers' use of the tip-sheet and encouraged its continued use during their three following weeks (S3-ii). This session added to the caregiver's recognition of herself as the organizer and creator of a healthy lifestyle when facing increased time or workload requirements due to worsening care-receiver health status. The caregivers learned skills for adjusting self-care activities when these issues occurred.

Material: Tip-sheet for self-care activities.

4.

Session Four (S4). Being positive in expressing the feelings to husbands

A joint session including the caregiver's spouse was conducted between S3-i and S3-ii. After obtaining signed informed consent, the spouse was encouraged to verbally express any thoughts regarding the caregiver's oppressed feelings or demands and provision of emotional support for and task-sharing with the caregiver. Spouses' current interpersonal support was re-examined by engaging with both spouses during this session, which helped the caregiver to feel free to express her feelings or demands regarding emotional support and task sharing to her spouse. By providing knowledge regarding what the spouse thought about the caregiver or caregiving for the agingparent, it further strengths the caregiver's feeling of acceptance by spouse.

Material: A joint session was conducted with both spouses serves, which served as an educational resource for caregivers in terms of feeling of acceptance by spouse.

5.

\section{Session Five (S5). Defining yourself as capable of problem solving}

In the final session, which was conducted one week after S4, the caregivers participated in an exit interview and post-intervention test.

The interview helped the caregiver to internalize a new view of herself as a skilled woman who was confident in problem solving and had a spouse capable of providing interpersonal support rather than solely participating in tasksharing.

Material: Post-intervention test.

Contents of the booklet from Hashizume (2010) [7]; tip-sheet for self-care activities from Colburn K (2003) The Women's Book of Simple Delights: Running press: PA; writing log from Pennebaker (2004) [24].

\section{Measurements of the short-term impact of the in- tervention}

Standardized questionnaires with established validity and reliability were used to measure the conceptual outcomes. Some items were developed. Demographic data were obtained through methods of self-reporting.

Expression of feelings was measured in three mea- surements: The Measure of Self Expression [27], a single question on the meaningfulness of the writing experience [24], and task-sharing. For the MSE, an index was computed by adding the scores obtained for two items (expressing to spouse caregiving for aging parents and feelings of isolation) from the overall scale. Response options ranged from two (never) to 10 (fully). The Cronbach's alpha coefficient for the overall scale among Japa- 
Citation: Hashizume Y (2018) The Coping with the Oppressed Feelings Program: A Pilot Feasibility Study for Employed Female Caregivers of Aging Parents. J Nurs Pract 2(2):62-72

nese college students was 0.92. Meaningfulness of the log included caregivers' remarks on the experience of completing the log each day, which served to check the effectiveness of the manipulation of the $\log$ [26]. Responses ranged from one (never) to 10 (fully). A score above five denoted a higher skill of expression [24]. Task-sharing was measured using one item for the caregiver, which asked if she shared the task of caregiving with her spouse (yes or no).

Acceptance by spouse was measured using one item for the caregiver, which asked whether the caregiver felt accepted by her spouse the way she was (yes, no, neither, unknown).

Self-care was measured using one item from the total scale of the Actual Private Space Function Scale (APSF-S) [28] as well as the self-reported self-care time during weekdays (weekday time) and weekends (weekend time). APSF-S asked for the caregivers' levels of actualization of securing time for rest and relaxation. Responses ranged from one (not secured) to four (fully secured). Higher scores denoted a higher level of actualization in securing time for self-care activities. Cronbach's alpha coefficient for the Japanese college students was 0.83 for the total scale.

Caregiving burden was measured using the Japanese Zarit Burden Interview (J-ZBI), a 22 item self-report inventory that examined the caregivers' strain. Response options ranged from zero to 88 . A higher score denoted a higher strain. Cronbach's alpha internal consistency reliability coefficient with Japanese subjects was 0.93 [29].

Gender pressure was measured using the Scale of Egalitarian Sex Role Attitude-short version (SESRA-S), a 15 item self-report inventory that examined the level of norm consciousness in terms of gender pressure. Response options ranged from 15 to 75 . A higher score indicated the perception of less pressure. Cronbach's alpha internal consistency reliability coefficient with Japanese college graduate students and spouse subjects was 0.91 [30].

Depressed mood was measured by the Center for Epidemiologic Studies-Depression Scale (CES-D), a 20 item self-report measurement of the psychological and physical symptoms of depressed mood [31]. Response options ranged from zero to 60 . The cut-off point was 16 and above. Reliability of Spearman-Brown formula for Japanese adults was 0.79 .

Role acceptance was measured using eight items from the Role Acceptance Scale (RAS), which assessed caregivers' satisfaction with their current role. Response options ranged from eight to 40. A higher score indicated higher satisfaction with their current role as a female working caregiver. The Cronbach's alpha coefficient for the Japanese general population has been reported to be 0.87 for the total scale [32].
Pre- and post-test scores were obtained for all the measurements.

To assess the gains and changes in caregiver skills, including expression of feelings, acceptance by spouse, selfcare and task-sharing, the interview data was obtained during the sessions and in the exit interview. The caregivers were asked 1) After participating in the session, have your feelings concerning the life of caregiving, including how to manage valuing your own time for self-care, changed? 2) What about sharing tasks with your spouse? and 3) Any reaction from your husband concerning your provision of a life of caregiving?

\section{Data Analysis Strategy}

Prior to evaluating the short-term impact of the intervention, the distribution and presence of outliers and the floor and ceiling effects in the data were assessed. Given the small sample size of this study, the author was interested in describing the changes in median scores and in testing their significance using two-tailed, non-parametric tests $[33,34]$. Specifically, the Wilcoxon signed-rank test was used to evaluate the differences between preand post-intervention scores. IBM SPSS Statistics for Windows, version 23.0, was used to analyze the descriptive data. Statistical significance was set at $P=0.05$; the presence of a significant trend was indicated at $P<0.10$.

The interview data obtained during the sessions were digitally audio-recorded and converted into verbatim transcriptions, and their contents were analyzed and extracted as complete ideas or a manifest meaning in either a noun or verbal expression [35]. Data were collected between November 2011 and May 2013.

\section{Ethical Considerations}

The study was conducted after obtaining approval from the IRB of the University of Tsukuba, Faculty of Medicine (No. 23-249, 23-249-1, 23-249-2, 23-249-3, 940). NE gave a written statement to the participants, which explained the study's purpose, methods, voluntary basis of participation and protection of anonymity based on the Declaration of Helsinki. For each participant, NE explained that the collected data would be used for the current study, specifically, and obtained signed, informed consent.

\section{Results}

\section{Description of the study sample}

A total of eight caregivers participated in the study. Four were nurses, and the rest were care-workers. Four participants were full-time workers, and three were parttime. One caregiver retired before retirement age and ran a self-employed business. None of the participants worked night shifts. All the caregivers were middle-class 
Citation: Hashizume Y (2018) The Coping with the Oppressed Feelings Program: A Pilot Feasibility Study for Employed Female Caregivers of Aging Parents. J Nurs Pract 2(2):62-72

with, at a minimum, a high school education. The caregivers were between 45 and 65-years-old (mean 57.50 $\pm 7.86)$. The length of time spent caring for their aging parent ranged from 1 to 8 (mean $5.1 \pm 2.67$ ) years. Their weekly hours of employment were between 4 and 50 (mean $29.4 \pm 16.72$ ) hours. These demographic characteristics were similar to those observed in Japanese middle-aged, employed females in national census data and existing intervention studies conducted with Japanese caregivers $[9,20,22]$. No changes in employment conditions were reported during the study.

There were eight care-receivers (aging parents), most of whom had dementia. Two were natural parents, and the rest were parent-in-laws. These care-receivers were between 80 and 102 (mean $89.38 \pm 7.70$ ) years old. One of the participants was home-bound, four were chairbound, and three were bed-bound. Four of the care-receivers lived with the caregiver, and three lived in the neighborhood. One care-receiver was institutionalized throughout the intervention. Two care-receivers were institutionalized during the intervention sessions. After completing the intervention, all the caregivers reported that the health status of their aging parents had deteriorated.

\section{Feasibility and Acceptability}

Completion rates of the intervention sessions: All eight caregivers completed all the intervention sessions at the planned interval, except the joint session (Session 4 ), which only $50 \%$ of the caregivers completed. The caregivers whose spouses declined shared the following three reasons for non-participation: the spouse was not interested in participating, the spouse was too busy because of his work or providing care, and the caregiving demand of the spouse was very low.

Completion rates of the at-home assignments: There were three at-home assignments: booklet reading, the log, and use of the tip-sheet. The completion rates were $100 \%$ for the booklet reading and $87.5 \%$ for the log. One caregiver did not complete the $\log$ at the planned interval and claimed that she did not have the time to do so. However, this caregiver selected the log activity on the tip-sheet and submitted $\log$ contents to the NE throughout the intervention. Some caregivers mentioned that the booklet brought them many ideas of other working female caregivers' similar situations. The caregivers also shared that writing in the log was troublesome at the beginning but bored them on the last day.

For the tip-sheet, the completion rates were 100\% for Session 3-i and 75\% for Session 3-ii. The caregivers attributed the decline observed in the frequency of using the tip-sheet to the three following reasons: having no time for themselves, worsening health status of aging parent, and illness of the caregiver.

\section{Short-term impact of the intervention in the overall study sample}

See Table 2 for a summary of the study outcomes. The scores of meaningfulness of the $\log (Z=-2.229, P=$ $0.026)$, weekend time $(Z=-1.841, P=0.066)$, and $\mathrm{J}-\mathrm{ZBI}$ improved significantly $(Z=-1.863, P=0.063)$. No improvements occurred in the MSE, APSF-S, weekday time, SESRA-S, CES-D, or RAS scores. However, some median scores changed in an improved direction, including the concepts (measures) related to express the feelings (MSE, 6.00 vs. 7.00 ) and role acceptance (RAS, 24.00 vs. 25.00). Self-care (APSF-S) remained stable (2.00 vs. 2.00). However, weekday time (90.00 vs. 60.00 ) and gender pressure (60.50 vs. 58.50) decreased. Depressed mood, while the median scores were under the cut-off point, increased slightly at the post-test (14.50 vs. 15.00$)$.

\section{Caregiver-reported skills after program completion}

See Table 3. In addition to obtaining data on standardized measures, exit interviews were conducted in which the caregivers reported what was gained that they attributed to COFP participation. The caregivers reported improvements in expression offeelings, gaining self-care skills, and task-sharing, citing that they had been "released from the pressure of being a good caregiver" or "gained the skills for task-sharing to avoid troubling or dishonoring their spouses". These are typical examples of gender roles in Japan. Even individuals who showed no improvement provided reasons for the identification of such outcomes. For example, the caregivers described gaining skills in selfcare, claiming that "before participating in the program, taking time for myself invoked judgement that I was a bad caregiver" (ID4). Caregivers who did not experience improvements in task-sharing shared the following reasons: desire to avoid troubling her spouse because he was too busy at work and the provision of care to the caregiver's own parent (ID3). Caregivers improved upon these skills and described how they involved their husbands in tasks by "cautiously expressing their demands and avoiding dishonoring him" (ID8). Four caregivers (ID1, 2, 4, 5, 50\%) reported that their spouses shared tasks upon entry into the study (ceiling effect).

For acceptance by spouse, the caregivers' participation in Session 4 further improved their skills in expression of feelings; thus, they gained the acceptance (ID3, 4). At that same time, claims voiced by caregivers implied that discussions with spouses concerning caregiving or oppressed feelings or demands occurred infrequently, unless the couple made an effort (ID1 spouse, ID7).

Additionally, spouses indicated that they exhibited poor listening skills when their wives were expressing the feelings, which was attributed to attitudes associated with the male 
Citation: Hashizume Y (2018) The Coping with the Oppressed Feelings Program: A Pilot Feasibility Study for Employed Female Caregivers of Aging Parents. J Nurs Pract 2(2):62-72

Table 2: Pre- and post-intervention standardized measurement scores for the overall study sample.

\begin{tabular}{|c|c|c|c|c|c|}
\hline Concepts, Measures & & Score range & Mean (SD) & Median & $P$-value \\
\hline \multicolumn{6}{|l|}{ Expression of feelings } \\
\hline \multirow[t]{2}{*}{ MSE§ } & Pre-test & $3-9$ & $6.43(1.40)$ & 6.00 & \\
\hline & Post-test & $4-9$ & $6.67(1.03)$ & 7.00 & 0.705 \\
\hline Meaningfulness & Day1 & $4-8$ & $6.29(1.60)$ & 7.00 & \\
\hline \multirow[t]{3}{*}{ of the $\log ^{\ddagger}$} & Day2 & $3-9$ & $5.71(2.06)$ & 5.00 & \\
\hline & Day3 & $5-9$ & $7.14(1.57)$ & 8.00 & \\
\hline & Day4 & $6-10$ & $8.00(1.29)$ & 8.00 & $0.026 \S \S$, \\
\hline \multicolumn{6}{|l|}{ Self-care } \\
\hline \multirow[t]{2}{*}{ APSF-S§ } & Pre-test & $1-3$ & $1.75(0.71)$ & 2.00 & \\
\hline & Post-test & $1-3$ & $1.88(0.64)$ & 2.00 & 0.564 \\
\hline \multirow[t]{2}{*}{ Weekday time ${ }^{\S}$} & Pre-test & $0-120$ & $78.33(49.97)$ & 90.00 & \\
\hline & Post-test & $30-240$ & $76.25(67.18)$ & 60.00 & 1.000 \\
\hline \multirow[t]{2}{*}{ Weekend time ${ }^{\S}$} & Pre-test & $0-360$ & $110.00(103.34)$ & 90.00 & \\
\hline & Post-test & $0-360$ & $157.50(106.07)$ & 120.00 & $0.066^{\dagger}$ \\
\hline \multicolumn{6}{|l|}{ Caregiving burden } \\
\hline \multirow[t]{2}{*}{$\mathrm{J}-\left.\mathrm{ZBI}\right|^{\dagger+}$} & Pre-test & $10-73$ & $48.50(20.51)$ & 49.00 & \\
\hline & Post-test & $2-73$ & $39.75(25.45)$ & 45.50 & $0.063^{\dagger}$ \\
\hline \multicolumn{6}{|l|}{ Gender pressure } \\
\hline \multirow[t]{2}{*}{ SESRA-S§ } & Pre-test & $57-62$ & $60.13(1.96)$ & 60.50 & \\
\hline & Post-test & $57-71$ & $62.13(6.06)$ & 58.50 & 0.498 \\
\hline \multicolumn{6}{|l|}{ Depressed mood } \\
\hline \multirow[t]{2}{*}{ CES-D+† } & Pre-test & $3-40$ & $17.38(11.43)$ & 14.50 & \\
\hline & Post-test & $4-49$ & $17.50(14.31)$ & 15.00 & 0.833 \\
\hline \multicolumn{6}{|l|}{ Role acceptance } \\
\hline \multirow[t]{2}{*}{$\mathrm{RAS}^{\S}$} & Pre-test & $15-30$ & $23.88(5.00)$ & 24.00 & \\
\hline & Post-test & $11-32$ & $24.13(7.24)$ & 25.00 & 0.892 \\
\hline
\end{tabular}

$N=8$. APSF-S: Actual Private Space Function Scale from Tomari and Yoshida (2004) [28]; CES-D: Center for Epidemiologic Studies-Depression Scale from Shima, Shikano, Kitamura, and Asai (1985) [31]; Expression of feelings: express the oppressed feelings or demands; Gender pressure: Japanese gender role pressure; J-ZBI: Japanese Zarit Burden Interview from Arai, et al. (1997) [29]; Meaningfulness of the log from the log writing exercise from Pennebaker (2004) [24], which was measured after the caregiver completed the writing log for each 4 days. There was one missing value as a caregiver did not complete the writing log at the planned interval; MSE: Measure of Self Expression from Shimada and Satoh (1999) [27]; RAS: Role Acceptance Scale from Mikawa (2004) [32]; SESRA-S: Scale of Egalitarian Sex Role Attitudes-short version from Suzuki (2004) [30]; Weekday time: self-care time (minutes) on weekdays; Weekend time: self-care time (minutes) during the weekends.

SD: Standard Deviation. ${ }^{\S} \mathrm{A}$ higher score indicates improvement. ${ }^{\dagger \dagger} \mathrm{A}$ lower score indicates improvement. ${ }^{\ddagger} \mathrm{A}$ score above 5 indicates improvement.

The Wilcoxon signed-rank test (two-tailed) was used to evaluate the differences between pre- and post-intervention scores. $\S \S$ Meaningfulness of the log was evaluated the differences between the Day 1 and 4 .

${ }^{*} P<0.05,{ }^{\dagger} P<0.1$.

gender role and was further correlated with the caregivers' acceptance by spouse. In fact, during interviews with the caregiver or couples conducted in Session 4, post-intervention improvements in three caregivers were revealed (ID3, 4, 5; 37.5\%). However, there were no improvements identified in the remaining five caregivers; one caregiver (ID8) changed to a negative perception of acceptance; one caregiver (ID1; S4 participant) maintained a positive perception; and the remaining three caregivers (ID6, 7, one Session 4 participant; ID2) remained negative throughout the study. Following the intervention, a caregiver that improved her acceptance by spouse claimed, "the joint session was the FIRST TIME I was able to understand my husband's thoughts on caring for his mother" (ID4). Moreover, one spouse expressed the following when asked how he listened to his wife's feelings or demands: "Because I am a male, I cannot" (ID4 spouse).

\section{Discussion}

\section{Hypothesis 1: The caregivers feel released from oppressed feelings or demands by raising aware- ness and normalizing them}

Meaningfulness of the log and caregiving burden (J-ZBI) changed significantly at the post-test; however, no improvement occurred in gender pressure (SESRA-S). Based on the 
Citation: Hashizume Y (2018) The Coping with the Oppressed Feelings Program: A Pilot Feasibility Study for Employed Female Caregivers of Aging Parents. J Nurs Pract 2(2):62-72

Table 3: Interview data obtained during the sessions and in the exit interview (Session five).

\section{Item}

Q: After participating in the session, have your feelings concerning the life of caregiving, including how to manage valuing your own time for selfcare, changed?

Q: What about sharing tasks with your spouse?

\section{Complete idea}

1) Released from the gender role pressure of being a good caregiver

2) Gaining self-care skill

3) Expressing demand of caring self

Gaining skills for task sharing in order to avoid troubling or dishonoring spouse

$Q$ : Any reaction from your husband concerning your provision of a life of caregiving?
1) Infrequently holding discussions with spouses concerning caregiving or express the feelings unless the couple made an effort

2) Improvement the skills in expressing the feelings; thus, they gain acceptance by spouse
Data (ex: informant ID)

A: Before participating in the program, taking time for myself invoked judgement that I was a lazy, bad caregiver. Now, I feel OK if I save time for myself and I feel more relaxed than before. (ID 4)

A: Before this (participation to the program), I was totally overwhelmed. But now, I feel I am relieved from pressures as a caregiver. (ID 5)

A: During the program, my mother-in-law suffered an injury that required a significant increase in care; I used that opportunity, without directly stating so, to subtly urge my formerly-reluctant husband to share the care. (ID 8)

A: Since there is no other way, so we TRY to discuss details and do it. (ID 1 spouse in Session 4)

A: (Reasons for not discussing about caregiving with spouse) Maybe because his awareness of caregiving is pretty low. So is mine. (ID 7)

A: (Reasons for not asking task sharing with spouse) Caregiving is for my own mother, so I do not ask my husband to give her care. I did not talk about caregiving with him, too. After the joint session, my husband suggested me remodeling our house. He has never given me such advice. That session (Session 4) really works ! (ID3)

A: That joint session (Session 4) was the first time

I was able to understand my husband's thoughts on caring for his mother. (ID 4)

3) Effects of gender role attitude for spouse interpersonal support to his wife (the caregiver)

A: I should express my gratitude toward my wife in words, but I am unable to actually do so, because I am a male, I cannot. (ID 4 spouse, written comments in the booklet)

(MSE) to the spouse. Further, in their statements, the caregivers reported improvements in expressing their feelings or task-sharing. Typical examples of gender roles in Japan were confirmed, such as avoiding troubling or dishonoring spouses. Moreover, the caregivers shared that they infrequently held discussions with spouses concerning caregiving or oppressed feelings, unless the couple made an effort.

The consequences of lack of improvement in the caregivers' expression of feelings might be rooted in their recognition that talking about caregiving or their aging parents would be troublesome for their spouses; therefore, that expression was disturbed. Corporate managers often find it difficult to grasp that working caregivers for aging parents need assistance in balancing their job and life compared to child-raising workers. The main reason has been assumed to be that caregiving for aging parents is difficult to tell others about, as it contains negative images [36]. Furthermore, the current study participants were nurses or care-workers. These formal caregivers have been reported to have tendencies that include avoiding disclosure of or consulting about personal problems related to work with their supervisors $[37,38]$. In light of this, one of the reasons for caregivers to have been disturbed to express their feelings might have been related to this recognition by the formal caregivers. These argu-

No improvement occurred in expressing of feelings 
Citation: Hashizume Y (2018) The Coping with the Oppressed Feelings Program: A Pilot Feasibility Study for Employed Female Caregivers of Aging Parents. J Nurs Pract 2(2):62-72

ments additionally affect the lack of improvements to the depressed mood (CES-D) or role acceptance (RAS) for formal caregivers in the context of work-related stressors [37]. In the current study, while it was under the cut-off point, the median score of the CES-D increased slightly at the post-test (14.50 vs. 15.00). The caregiving of personal, aging parents by formal caregivers has been suggested to be a different experience compared to caregiving as an occupation [39]. Therefore, future research is needed to explore how the caregiving experience of personal, aging parents is different than their occupational phenomenon and its impact on caregiving-related stressors.

\section{Hypothesis 3: The caregivers engage in self-care activities on a more regular basis.}

Self-care time during the weekends improved significantly at the post-test. Furthermore, caregivers shared that they had been released from the gender role pressure of being a good caregiver after the program, which made them feel fine about saving their own time. However, no improvements occurred in APSF-S and self-care time on weekdays. At the post-test, the median of the weekday time (60 minutes) was much shorter than the average length of time allotted for wives in dual-income couples (130 minutes, Nagase Co., Ltd, 2013) [40]. Additionally, the completion rate of the tip-sheet was $100 \%$ for the first two weeks; however, it decreased to $75 \%$ in the next three weeks. The main reasons were lack of time for the caregivers or the worsening of health status of the aging parents or caregivers. This result suggests a consideration of alternative measures to prepare for those sudden events as well as collaboration with other family members to manage the necessary tasks.

\section{Implications for Clinical Practice}

When compared to existing intervention studies of Japanese family caregivers [20-22], the current study was innovative in the following two respects: a) The caregivers engaged in discussions regarding the caregiving situation with an objective NE, who invited them to describe their situation. This initiation of disclosure has traditionally not been performed during interactions with Japanese women because their focus is supposed to be on protecting familial reputations and harmony. b) In this study, female caregivers participated in expressive exercises that are not common or normative for Japanese female caregivers. However, the caregivers gained motivation for self-care and attributed these positive changes to shifting away from caring for others to caring for oneself, which justifies the importance of the current program.

For formal caregivers, caregiving could be recognized as a "daily routine", or the typical activities in their everyday occupation. However, caregiving for one's own aging parents "may be associated with complex emo- tions, such as resentment about time and effort expended as well as sympathy and anticipatory loss of a loved one" [14, p.25]. The quote "I understand his/her dementia as a care-worker, but I cannot accept the reality" [39, p.68] denotes the difficulty of formal caregivers' caring for their own aging parents. Therefore, the effect of the program may be applicable to different stressors of formal caregivers related to providing substantial care for complex health problems, such as dementia or functional disabilities, to their aging parents.

\section{Conclusions}

The results of the analyses of the overall sample suggested that the intervention had an impact on three out of seven concepts (measures); the intervention increased the caregivers' expression of feelings (meaningfulness of the $\log$ ) and self-care time during the weekends, and it diminished their perceived caregiving burden (J-ZBI). Given the small sample size, these changes cannot be unconditionally interpreted as improved. The recruitment of eligible caregivers in culturally acceptable ways requires further study.

\section{Acknowledgements}

This work was supported by Grant-in-Aid for Scientific Research from the Japan Society for the Promotion of Science (JSPS), KAKENHI [grant numbers 21592883, 26463482]; and the Meiji Yasuda Mental Health Foundation Research award 2011.

I acknowledge Professor Frances Marcus Lewis of the University of Washington, School of Nursing for the enthusiastic support in the preparation of this article.

\section{Conflict of Interest}

No conflict of interest has been disclosed by the author.

\section{References}

1. Health, Labour and Welfare Statistics Association (2017) Static population, long-term-care-insruance. Journal of Health and Welfare Statistics 64: 50, 259.

2. Statistics Bureau (2013) Employment status survey.

3. Gender Equality Bureau Cabinet Office (2015) Trends in female labor force ratio by age group.

4. Morito, $H(2004)$ A point of view on failure of national pension plan. Julist 1260: 1-15.

5. Sekigawa Y (2004) Households behavior after bubble-economy collapsed. Nagoya Bunri University Bulletin 4: 33-42.

6. The House of Representatives (2011) Law for partial amendment of any such long term care insurance law for strengthen the basics.

7. Hashizume $Y(2010)$ Releasing from the oppression: caregiving for the elderly parents of Japanese working women. Qualitative Health Research 20: 830-844. 
Citation: Hashizume Y (2018) The Coping with the Oppressed Feelings Program: A Pilot Feasibility Study for Employed Female Caregivers of Aging Parents. J Nurs Pract 2(2):62-72

8. Oshima $Y$ (2012) Fear for resining job for dealing with family careiving.

9. Gender Equality Bureau Cabinet Office (2011) Circumstances of society with gender equality. In White report on society with gender equality 2011 .

10. Hosaka T (2011) Condition and support service for depressed mood of home-based family caregivers. The Japanese Journal for Public Health Nurse 67: 250-253.

11. Tsuchiya M, Kawakami N, Ono $\mathrm{Y}$, Nakane $\mathrm{Y}$, Nakamura $Y$, et al. (2012) Impact of mental disorders on work performance in a community sample of workers in Japan: the world mental health Japan survey 2002-2005. Psychiatry Research 198: 140-145.

12. Minegishi T, Shiwatari K (2015) Depressed mood among female care-worker and related factors. Journal of Hokkaido Sciences University of Hokkaido, School of Nursing and Social Services 11: 37-42.

13. Ministry of Heatlh, Labor, and Welfare (2011) Nursing staff employment situation and actual situation survey result.

14. Hashizume $Y(2000)$ Gender issues and Japanese family-centered caregiving for frail elderly parents or parents-inlaw in modern Japan: from the sociocultural and historical perspectives. Public Health Nursing 17: 25-31.

15. Kagawa-Singer M, Wellisch DK (2003) Breast cancer patients' perceptions of their husbands'support in a cross-cultural context. Psychooncology 12: 24-37.

16. Hirayama J, Kashiwagi K (2001) Attitudes of Married Couples toward Communication: Husband/ Wife Comparisons. The Japanese Journal of Developmental Psychology 12 : 216-227.

17. Kashiwagi K (2013) Prerequisite for being an adult. Tokyo: Iwanami shoten.

18. Recruit Marketing Partners Co., Ltd, Research \& Development (2012) Survey on the marital relationship in 2012.

19. Institute of statistical research for gender-equal society (Ed.) (2015) Statistical data book on gender equality, Gyosei, Tokyo.

20. Mochizuki N (2005) Effects of psychoeducational intervention program on family caregivers of the frail older adult. Journal of Japan Academy of Gerontological Nursing 10: 17-23.

21. Ono K, Kanayama Y, Yabuwaki K (2013) Systematic review of intervention efficacy targeting family caregivers of the older adult. Japanese Journal of Geriatric Psychiatry 24: 383-392.

22. Suganuma M, Nitta S (2014) The effectiveness of a peer support group program for female caregivers of the older adult with dementia. Journal of Japan Academy of Gerontological Nursing 19: 81-90.

23. Sorensen S, Pinquart M, Duberstein P (2002) How effective are interventions with caregivers? An updated meta-analysis. The Gerontologist 42: 356-372.

24. Pennebaker JW (2004) Writing to Heal. New Harbinger Publications, California.
25. Baranowski T, Perry CL, Parcel GS (2002) Social cognitive theory. In: K Glanz, BK Rimer, FM Lewis, Health Behavior and Health Education: Theory, Research, and Practice. ( $3^{\text {rd }}$ edn), Jossey-Bass, California, 165-184.

26. Mackenzie CS, Wiprzycka UJ, Hasher L, Goldstein D (2007) Does expressive writing reduce stress and improve health for family caregivers of older adults? The Gerontologist 47: 296-306.

27. Shimada H, Satoh K (1999) Development of self-expression scale and its psychological significance. Humanities Research 101: 17-34.

28. Tomari S, Yoshida T (2004) Private space function scale. In: H Hori, T Yoshida, Psychometric scale collection II. Saiensu, Co. Ltd, Tokyo, 427-435.

29. Arai Y, Kudo K, Hosokawa T, Washio M, Miura H, et al. (1997) Reliability and validity of the Japanese version of the Zarit Caregiver Burden interview. Psychiatry Clin Neurosci 51: 281-287.

30. Suzuki J (2004) Review of gender research in cross-cultural psychology since 1990s: conceptual and methodology. The Japanese Journal of Psychology 75: 160-172.

31. Shima S, Shikano T, Kitamura T, Asai M (1985) New self-rating scale for depression. Clinical Psychiatry 27: 717-723.

32. Mikawa T (2004) Role acceptance scale. In: H Hori, T Yoshida, Psychometric scale collection II. Tokyo: Saiensu, Co., Ltd. 297-300.

33. Lewis FM, Alzawad Z, Griffith K, Almulla H, Wu P, et al. (2017) Taking care of her: a pilot feasibility study of a caregiver intervention for women with advanced stage ovarian cancer. Journal of Cancer Therapy 8: 472-489.

34. Siegel S, Castellan NJ (1988) Nonparametric Statistics for the behavioral Sciences. ( $2^{\text {nd }}$ edn), McGraw-Hill. New York, USA.

35. Lewis FM, Haberman MR, Wallhagen MI (1987) How adults with late-stage cancer experience personal control. Journal of Psychosocial Oncology 4: 27-42.

36. Kosone $Y$ (2011) What the company is able to work on immediately for "supporting balancing work and caregiving for the elderly".

37. Sasagami A, Aijyo R, Nguyen T, Katayama K, Nagata K, et al. (2017) Burnout-related effects of emotional labor and work-related stressors among psychiatric nurses in Japan. Journal of Wellness and Health Care 41: 97-111.

38. Tao M (1987) Burnout theory and its measurement in human services. The scientific reports of Kyoto Prefectural University: humanities 39: 99-112.

39. Arai $H$ (2013) A qualitative study on supporting difficult cases of social work. Journal of Japanese Journal of Gerontology 35: 67-75.

40. Nagase Co., Ltd (2013) Survey on work-life balance of female workers. 